\title{
Simulation on the Two-phase Separation of Powder Injection Molding 316L Stainless Steel
}

\author{
Feng SHANG ${ }^{1,2,3}{ }^{*}$, Bin QIAO ${ }^{1}$, Yan-feng DONG ${ }^{4}$, Zhen-wei CAO ${ }^{4}$, Wei SUN ${ }^{1}$, Yi-qiang HE ${ }^{1}$ \\ ${ }^{1}$ School of Mechanical Engineering, Huaihai Institute of Technology, Lianyungang 222005, China \\ ${ }^{2}$ Marine Resources Development Institute of Jiangsu, Lianyungang 222001, China \\ ${ }^{3}$ Jiangsu Key Laboratory of Large Engineering Equipment Detection and Control, Xuzhou Institute of Technology Xuzhou \\ 221111, China \\ ${ }^{4}$ School of Mechanical and Electrical Engineering, China University of Mining and Technology, Xuzhou 221116,China
}

cross $^{\text {ref }}$ http://dx.doi.org/10.5755/j01.ms.25.3.19137

Received 27 September 2017; accepted 10 June 2018

\begin{abstract}
By utilizing the FLUENT software, finite element simulation analysis was performed on the two-phase separation of powder injection molding, and the simulation results were verified through experiment. As indicated in the simulation results, the optimal process parameters for the injection molding of 316L stainless steel sample were to inject at $70 \mathrm{MPa}$ and $140{ }^{\circ} \mathrm{C}$, at an injection speed of $3.49 \mathrm{~cm}^{3} / \mathrm{s}$. Under these conditions, the maximum average solid volume fraction in observation area of the sample was $57.68 \%$. Additionally, it was discovered that while preparing $316 \mathrm{~L}$ stainless steel was prepared by powder injection molding, the smaller the average porosity of the sample, the greater the Vickers hardness. And then the higher the average solid volume fraction simulated the slighter the two-phase separation between the powder and the binder.
\end{abstract}

Keywords: powder injection molding, simulation, 316L stainless steel, two-phase separation.

\section{INTRODUCTION}

As a kind of new near-net shape forming technology for producing metal or ceramics parts, powder injection molding (PIM) integrates the injection molding with the traditional powder metallurgy process [1,2]. PIM technology is characterized by high processing efficiency, in which subsequent cuttings can be basically dispensed with high material utilization. Meanwhile, it can overcome defect existing in the traditional powder metallurgy products such as the great density gradient. Additionally, the product made by this technology is of high mechanical property, which is beneficial for the realization of automatic production, and can be produced in large scales. Hence, this technology has been widely applied in fields including automobile [3, 4], biological and medical device $[5,6]$, etc.

It is crucial to ensure the reproducibility of precision and avoid defects in the mass production of the powder injection molding technology [7-9]. The reproducibility of precision refers to that the precision of the final sintered product can meet requirements of the drawing. Therefore, no over severe two-phase separation is permitted in the PIM green body, so as to ensure the isotropic contraction of the green body in sintering process. Many studies have been conducted on the two-phase separation of feedstock by scholars at home and abroad concerning. German et al. [10] found that the greater the density difference between the powder and binder, the easier it is to separate the two phases. Shivashankar et al. [11] found that small particle spacing or low lubrication fluid content will aggravate the

\footnotetext{
* Corresponding author. Tel.: +0086-0518-85895323.

E-mail address: shangfeng@hhit.edu.cn(Shang Feng)
}

two-phase separation, it should avoid high powder loading in the actual PIM production. Wang Yuhui et al. [12, 13] found that the two fluid model was able to simulate the phenomenon of two-phase separation and powder aggregation commonly seen in PIM, and the two fluid model than Euler Lagrange model is easier to achieve the convergence condition. In this paper, the effects of injection pressure, injection temperature and injection speed on injection molding samples are investigated. The FLUENT software was employed in the research to simulate two-phase separation of the feedstock. The feasibility of two-phase flow model in $316 \mathrm{~L}$ stainless steel by powder injection molding is verified.It was discovered that the simulation results coincided with the experimental results, which provided theoretical basis for ensuring the reproducibility of precision and the avoidance of defects for product.

\section{EXPERIMENTAL PROCEDURE}

As to the experimental conditions, by using the powder of $316 \mathrm{~L}$ stainless steel with particle size of $2 \sim 30 \mu \mathrm{m}$, and loading capacity(vol.\%) of the injected feedstock powder of $58 \%$ [14], the paraffin based binder comprising $65 \%$ (wt.\%) of paraffin, $30 \%$ (wt.\%) of low density polyethylene and $5 \%$ (wt.\%) of stearic acid, was adopted [14]. Powder and binder were mixed at $140{ }^{\circ} \mathrm{C}$ for 2 hours. Table 1 shows the physical parameters of feedstock and binder. The physical parameters of the binder were weighted according to the volume fraction of each component. The physical parameters of the feedstock were weighted according to the mass fraction of each component. The injection processing parameters were obtained by orthogonal optimizing experiment, and the 
optimized results are shown in Table 2. The mould was at room temperature, namely $300 \mathrm{~K}$.

HAAKE PolyLab torque rheometer was used to prepare feedstock, Haitian SA600 injection molding machine was used to injection molding, WZDS-20 vacuum sintering furnace was used for vacuum thermal debinding and sintering, HV-30 Vickers hardness tester was used for measuring the hardness of green sample, Axio vert.A1 microscope was used for observing the microstructure of samples.

Table 1. Physical parameters of feedstock and binder

\begin{tabular}{|c|c|c|c|}
\hline Component & $\begin{array}{c}\text { Density, } \\
\mathrm{kg} \cdot \mathrm{m}^{-3}\end{array}$ & $\begin{array}{c}\text { Thermal } \\
\text { conductivity } \\
\text { coefficient, } \\
\mathrm{W} \cdot \mathrm{m}^{-1} \cdot \mathrm{K}^{-1}\end{array}$ & $\begin{array}{c}\text { Specific } \\
\text { heat } \\
\text { capacity, } \\
\mathrm{J} \cdot \mathrm{K}^{-1} \cdot \mathrm{kg}^{-1}\end{array}$ \\
\hline PW & 910 & 0.14 & 2700 \\
\hline LDPE & 920 & 0.32 & 2301 \\
\hline SA & 960 & 0.35 & 1700 \\
\hline $\begin{array}{c}\text { 316L stainless } \\
\text { steel }\end{array}$ & 7930 & 16.2 & 500 \\
\hline binder & 915.4 & 0.2045 & 2530.3 \\
\hline feedstock & 4983.9 & 14.9672 & 656.49 \\
\hline
\end{tabular}

\section{MATHEMATICAL MODEL}

\subsection{Basic assumption}

While the mould cavity was filled by using the powder injection molding technology, merely the powder phase and binder phase were taken into account, while the air phase in the cavity was ignored.

\subsection{Mathematical model}

The continuity equation of the two-phase flow model is given as follow [15]:

$$
\frac{\partial}{\partial t}\left(f_{p} \rho_{p}\right)+\nabla \cdot\left(f_{p} \rho_{p} \mathbf{V}_{p}\right)=0
$$

where: $p$ represents the binder phase $l$ and the solid powder phase $s$ respectively; $f_{p}$ indicates respectively the mass fraction of binder phase and powder phase, and here $f_{l}+f_{s}$ $=1 ; \rho_{p}$ is the density of each phase; $V_{p}$ denotes the volume of fluid micelle.

The momentum equation is:

$$
\begin{aligned}
& \frac{\partial(\rho u)}{\partial t}+\frac{\partial\left(\rho u^{2}\right)}{\partial x}+\frac{\partial(\rho u v)}{\partial y}+\frac{\partial(\rho u w)}{\partial z}=-\frac{\partial p}{\partial x} \\
& +\frac{\partial}{\partial x}\left(\lambda \nabla \cdot \mathbf{V}+2 \eta \frac{\partial u}{\partial x}\right)+\frac{\partial}{\partial y}\left[\eta\left(\frac{\partial v}{\partial x}+\frac{\partial u}{\partial y}\right)\right] \\
& +\frac{\partial}{\partial z}\left[\eta\left(\frac{\partial u}{\partial z}+\frac{\partial w}{\partial x}\right)\right]+\rho g_{x}+U_{p i j}
\end{aligned}
$$

The left side of the equation represents the rate of momentum variation of the actual fluid microcluster with time. The first item is caused by the non-stationarity of the flow, the second item is due to the uneven distribution of velocity in the flow field. The right of the equation represents the actual force in the direction of motion which is composed of volume force and surface force. The volume force includes gravity $f_{p} \rho_{p}$ g and so on. The surface forces include pressure, viscous force (normal stress and shear stress), dragging force $U_{p i j}$ and so on.

The energy equation is:

$$
\begin{aligned}
& \frac{\partial}{\partial t}\left[\rho\left(e+\frac{V^{2}}{2}\right)\right]+\nabla \cdot\left[\rho\left(e+\frac{V^{2}}{2}\right) V\right] \\
& =-\rho \dot{q}+\frac{\partial}{\partial y}\left(k \frac{\partial T}{\partial x}\right)+\frac{\partial}{\partial y}\left(k \frac{\partial T}{\partial y}\right)+\frac{\partial}{\partial z}\left(k \frac{\partial T}{\partial z}\right) \\
& -\frac{\partial(u p)}{\partial x}-\frac{\partial(v p)}{\partial y}-\frac{\partial(w p)}{\partial z}+\frac{\partial\left(u \tau_{x x}\right)}{\partial x}+\frac{\partial\left(u \tau_{y x}\right)}{\partial y} \\
& +\frac{\partial\left(u \tau_{z x}\right)}{\partial z}+\frac{\partial\left(v \tau_{x y}\right)}{\partial x}+\frac{\partial\left(v \tau_{y y}\right)}{\partial y}+\frac{\partial\left(v \tau_{z y}\right)}{\partial z} \\
& +\frac{\partial\left(w \tau_{x z}\right)}{\partial x}+\frac{\partial\left(w \tau_{y z}\right)}{\partial y}+\frac{\partial\left(w \tau_{z z}\right)}{\partial z}+\rho g \cdot V
\end{aligned}
$$

In the energy equation, the left side of the equation represents the rate of change of the energy per unit mass of fluid micelle with time; the right represents heat radiation, heat conduction, the work done by pressure to the unit mass fluid, the viscous dissipation term, and the gravity work.

According to the law of conservation of mass, conservation of momentum and conservation of energy, the control Eq. 1, Eq. 2 and Eq. 3 of the filling mold cavity in powder injection molding is obtained, and the momentum equation and energy equation are decoupled from the reuse Eq. 1, Eq. 2 and Eq. 3. The pressure field, temperature field and velocity field of the cavity are obtained.

The drag coefficient $C_{D}^{*}$ between the two phases in powder injection molding represents the force between the powder particles and the binder phase. $R e_{p}^{*}$ represents Reynolds number. The drag coefficients of the powder and the binder were that of the particle with non-circular crosssection investigated by Ganser et al. [16], as illustrated in Eq. 4. The drag coefficient between non spherical irregular particles and fluid can be imported into FLUENT, so that the subsequent simulation is more consistent with the actual filling process of powder injection molding.

$$
C_{D}^{*}=\frac{24}{\operatorname{Re}_{p}^{*}}\left[1+0.035\left(\operatorname{Re}_{p}^{*}\right)^{0.74}\right]+\frac{0.42}{1+\frac{33}{\left(\operatorname{Re}_{p}^{*}\right)^{0.5}}}
$$

In FLUENT 14.5, the two coefficient method and the three coefficient method are provided for the power law model, of which the three coefficient method is UserVisLaw model, and its expression is shown in Eq. 5. The double influence of temperature and shear rate on the viscosity of feed is taken into account, and the constant $m_{0}$ and $T_{a}$ can be solved by using the Matlab fitting. The rheological models of the melting feedstock of $316 \mathrm{~L}$ stainless steel and the binder are 


$$
\eta(\gamma, T)=1086.5 \exp (677.6 / T) \gamma^{-0.5} \text { and }
$$

$\eta=2.369 \times 10^{-10} e^{10736 / T} \gamma^{-0.71}$, respectively.

$$
\eta(\gamma, T)=m_{0} \exp \left(T_{a} / T\right) \gamma^{n-1} .
$$

where: $m_{0}$ and $T_{a}$ represents material constant, $n$ represents shear thinning index, $\eta$ represents viscosity, $\gamma$ represents shear rate.

\subsection{Boundary conditions}

1. The pressure and speed in the inlet boundary are known.

2. The pressure in the outlet boundary is standard atmospheric pressure.

3. With respect to the viscous flow, the mould wall is treated under no slip shear condition.

\subsection{Simulation method}

Filling process was affected by the basis of process parameters, finite simulation analysis was performed on the main driving factors of two-phase separation including the injection temperature, injection speed and so on. As to the two-phase separation simulated by two-phase flow model, the powder particle was applied as pseudo-fluid. Meanwhile, after determining viscosities of the feedstock and the binder, the equivalent viscosity of the powder was obtained through conversion. While simulating the molding of standard tensile sample of 316 stainless steel by injection of the powder, the two-phase flow model was utilized to analyze the solid volume fraction after filling. The ANSYS ICEM CFD was employed to divide the grid in the simulation process. Owing to the product was in two dimensional shape, the quadrilateral unstructured grid unit was applied in the grid to shorten the calculation time, as shown in Fig. 1. The grid consisted of 1,239 units and 1,095 nodes in total.

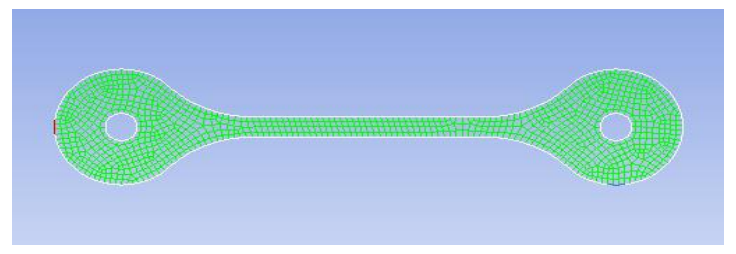

Fig. 1. Grid unit of sample

The solver in FLUENT was set as follows: based on the unsteady flow field, the pressure based solver was adopted to solve the coupling equations of the energy and the momentum by means of pressure-speed coupling under laminar flow. The solid volume fraction was calculated

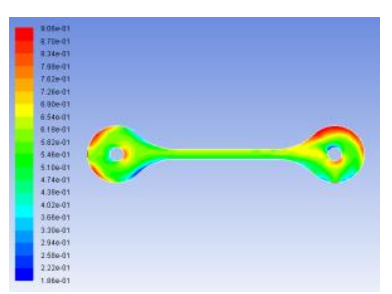

a

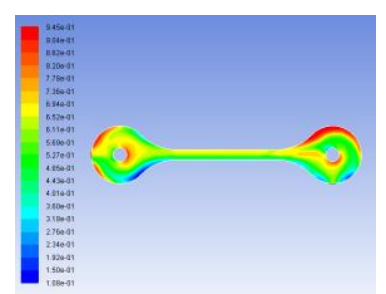

b

implicitly using the mixed model in two-phase flow, and the coupling equations of the energy and the momentum were calculated by adopting the phase coupling SIMPLEC. The torsion and correction coefficient of the grid was 1, the spatial discrete gradient was calculated using Green-Gauss node method, and other parameters were default. The under-relaxation factors consisted of the pressure of 0.2, momentum for 0.4 , and volume fraction of 0.2 , and other factors were default. In the initialization process, it was assumed that the binder phase and the powder phase shared with the same initial speed, temperature, drag model and heat transfer coefficient. Then the following parameters were given: speeds in $x$ and $y$ directions were respectively 0.2 and 0.5 , the temperature and the solid volume fraction were $300 \mathrm{~K}$ and 0.3 . The convergence criteria were set as follows: the continuity equation was $10^{-5}$, the momentum equation in direction of $x$ and $y$ was $10^{-4}$, the energy equation was $10^{-6}$ and the volume fraction equation was $10^{-4}$. Meanwhile, the time step was set as $0.001 \mathrm{~s}$ with 1000 iterative time steps, the maximum iterative number was 500 time steps.

\section{SIMULATION RESULTS AND ANALYSIS}

The filling processes of samples A-G are simulated respectively to investigate the two-phase separation of the powder and the binder in the experiment of injection molding of 316L stainless steel, as shown in Table 2. In the simulation calculation, the velocity inlet is utilized while the inlet pressure is ignored, and the influence of injection pressure on the product is considered to be smaller than that of the injection speed and temperature. As a result, simulation results of samples A and F, B and G, D and E are same. Fig. 2 illustrates the cloud picture of solid contents of A, B, C and D at $1 \mathrm{~s}$ successively. According to above analysis, the average solid contents are obtained for each group with different injection parameters in area A, as illustrated in Table 2.

Table 2. Process parameter of intact samples

\begin{tabular}{|c|c|c|c|c|}
\hline $\begin{array}{c}\text { The sample } \\
\text { number }\end{array}$ & $\begin{array}{c}\text { Injection } \\
\text { pressure, } \\
\mathrm{MPa}\end{array}$ & $\begin{array}{c}\text { Injection } \\
\text { temperature, } \\
{ }^{\circ} \mathrm{C}\end{array}$ & $\begin{array}{c}\text { Injection } \\
\text { speed, } \\
\mathrm{cm}^{3} / \mathrm{s}\end{array}$ & $\begin{array}{c}\text { Average } \\
\text { solid volume } \\
\text { fraction, } \%\end{array}$ \\
\hline Sample A & 70 & 140 & 3.49 & 57.68 \\
\hline Sample B & 70 & 140 & 5.59 & 57.66 \\
\hline Sample C & 70 & 160 & 3.49 & 57.38 \\
\hline Sample D & 70 & 150 & 3.49 & 57.53 \\
\hline Sample E & 80 & 150 & 3.49 & 57.53 \\
\hline Sample F & 90 & 140 & 3.49 & 57.68 \\
\hline Sample G & 90 & 140 & 5.59 & 57.66 \\
\hline
\end{tabular}

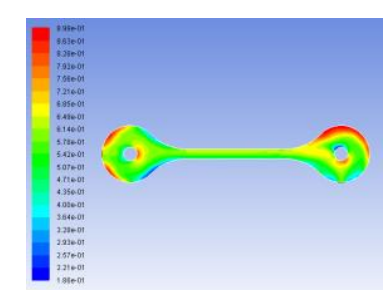

c

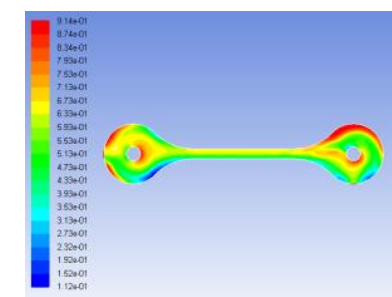

d

Fig. 2. Contours of solid volume fraction at the end of filling time: a-Samples A and F; b-Samples B and G; c-Samples C; d-Samples D and E 
As observed in the injection parameters of each group, the solid volume fractions of samples $\mathrm{A}$ and $\mathrm{F}$ is the same for $57.68 \%$, which demonstrates when other injection parameters remain constant, the injection pressure has little influence on the injection results. Therefore, low injection pressure is applicable in the practical injection, which can reduce requirement for the injection molding machine. Owing to the overquick injection speed, severe two-phase separation is generated in the injection process of samples $\mathrm{B}$ and G. After the follow-up process, large numbers of pores with great size, even pits, are likely to be generated on the product. All these can give rise to the product defects. Park et al. [17] has proved the relationship between binder viscosity and injection temperature, because of the high temperature, the viscosity of the binder is low and dragging force between the powder phase and the binder phase is small, resulting in large speed difference between the powder and the binder in the accelerated filling of sample $C$. As a result, large amounts of particles are deposited on the bottom of the cavity under the influence of gravity, which gives rise to the most severe two-phase separation. The solid volume fraction of sample C is $57.38 \%$. Both the solid contents of samples D and $\mathrm{E}$ are $57.53 \%$, which is basically the same with those of samples A and F. This verifies that when the injection speed is kept unchanged, within certain range, the influence of injection temperature on the two-phase separation of liquid and solid is equal to that of injection pressure. The results above basically correspond with that of the practical injection experiment.

\section{VERIFICATION ON THE EXPERIMENTAL RESULTS}

The orthogonal experiment was adopted in the injection experiment to obtain parameters of each group, in which samples had no apparent defect. Fig. 3 illustrates the gate location in the injection process.

According to the part structure, it is observed that in the final filling process, the weld line is generated on area A of the figure, which likely leads to various defects.
Therefore, the metallurgical microscope was employed to analyze the porosity in area A after injection molding.

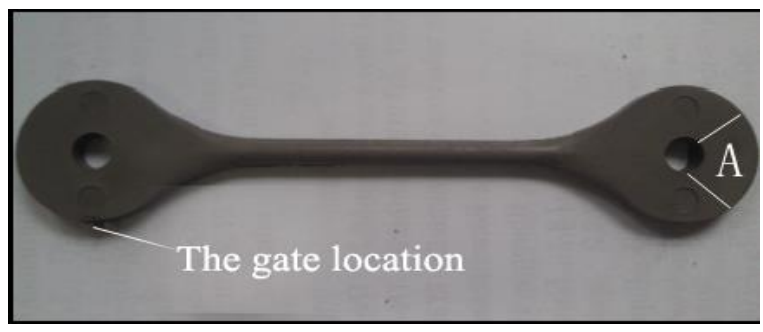

Fig. 3. The gate location of sample

Later, the analysis results were considered as index for judging severity of the two-phase separation between the binder and the powder. By observing the same location in area $\mathrm{A}$ of each sample using the metallurgical microscope with magnification times of 500, the pore in each group of sample can be observed in Fig. 4, where the black part represents holes. Table 3 demonstrates the average porosity of each group of sample calculated by the microscopic phase analysis.

As observed in the metallographic structure of each group of sample, because the injection speed of samples B and $\mathrm{G}$ was $40 \%$, the surface pore is therefore great in size and number. It was analyzed that when the injection speed was great, the particle density was greater than that of the binder, and therefore the particle was endowed with high inertia. On the contrary, due to the mutual involvement of the macromolecular binder, the speed of the binder was low. As a result, the high injection speed is easy to cause two-phase separation, and the place where binder gathered turned into pores after the subsequent debinding and sintering. The debinding and sintering curves are shown in Fig. 5. Furthermore, severe two-phase separation was generated on the weld line of sample G. In this way, all pores were formed along this line of the product, which affected mechanical properties of the product badly. As demonstrated in Table 4, the average Vickers hardness of sample $\mathrm{G}$ is the minimum. The porosities of samples $\mathrm{A}$ and $\mathrm{F}$ are basically the same.

Table 3. The average porosity of each group of sample

\begin{tabular}{|c|c|c|c|c|c|c|c|}
\hline Number & $\mathrm{A}$ & $\mathrm{B}$ & $\mathrm{C}$ & $\mathrm{D}$ & $\mathrm{E}$ & $\mathrm{F}$ & $\mathrm{G}$ \\
\hline 1 & $1.09 \%$ & $1.84 \%$ & $1.61 \%$ & $1.37 \%$ & $1.53 \%$ & $1.14 \%$ & $2.04 \%$ \\
\hline 2 & $1.12 \%$ & $1.71 \%$ & $1.66 \%$ & $1.62 \%$ & $1.44 \%$ & $1.11 \%$ & $2.18 \%$ \\
\hline 3 & $1.14 \%$ & $1.82 \%$ & $1.57 \%$ & $1.45 \%$ & $1.34 \%$ & $1.2 \%$ & $2.29 \%$ \\
\hline 4 & $1.2 \%$ & $1.55 \%$ & $2.00 \%$ & $1.37 \%$ & $1.41 \%$ & $1.38 \%$ & $2.15 \%$ \\
\hline 5 & $1.11 \%$ & $1.22 \%$ & $1.85 \%$ & $1.2 \%$ & $1.27 \%$ & $1.01 \%$ & $2.22 \%$ \\
\hline Average & $1.13 \%$ & $1.63 \%$ & $1.73 \%$ & $1.40 \%$ & $1.39 \%$ & $1.17 \%$ & $2.17 \%$ \\
\hline
\end{tabular}

Table 4. The average vickers hardness value of sample

\begin{tabular}{|c|c|c|c|c|c|c|c|}
\hline Number Sample & A & B & C & D & E & F & G \\
\hline 1 & 108 & 108 & 99 & 106 & 109 & 109 & 84 \\
\hline 2 & 113 & 105 & 102 & 107 & 111 & 99 & 89 \\
\hline 3 & 109 & 102 & 98 & 107 & 108 & 95 & 93 \\
\hline 4 & 113 & 104 & 107 & 106 & 104 & 102 & 89 \\
\hline 5 & 107 & 106 & 108 & 106 & 108 & 105 & 96 \\
\hline Average & 110 & 105 & 104 & 106.4 & 108 & 102 & 90.2 \\
\hline
\end{tabular}




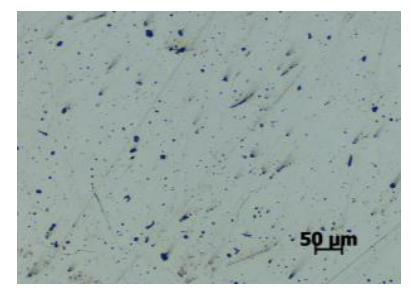

a

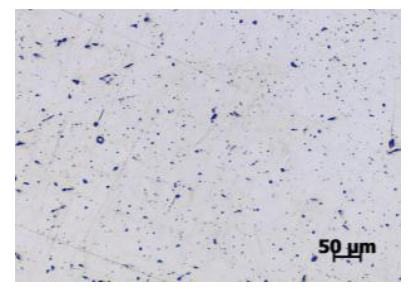

e

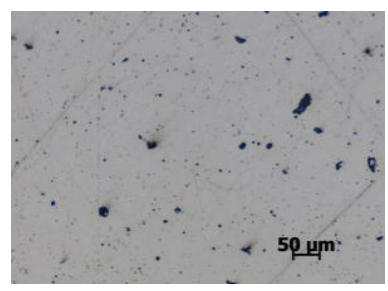

b

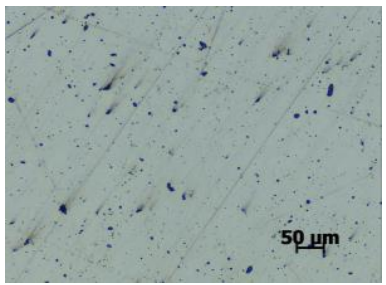

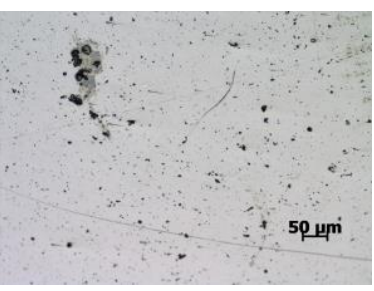

c

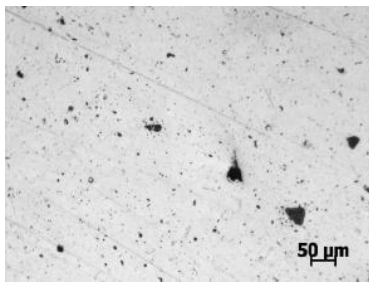

g

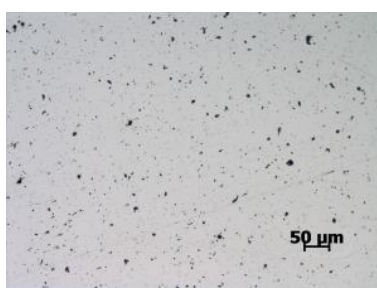

d

Fig. 4. Surface micro pores of each sintered sample: a-70 MPa, $140{ }^{\circ} \mathrm{C}, 3.49 \mathrm{~cm}^{3} / \mathrm{s} ; \mathrm{b}-70 \mathrm{MPa}, 140{ }^{\circ} \mathrm{C}, 5.59 \mathrm{~cm}^{3} / \mathrm{s}$; $\mathrm{c}-70 \mathrm{MPa}, 160{ }^{\circ} \mathrm{C}, 3.49 \mathrm{~cm}^{3} / \mathrm{s} ; \mathrm{d}-70 \mathrm{MPa}, 150{ }^{\circ} \mathrm{C}, 3.49 \mathrm{~cm}^{3} / \mathrm{s} ; \mathrm{e}-80 \mathrm{MPa}, 150{ }^{\circ} \mathrm{C}, 3.49 \mathrm{~cm}^{3} / \mathrm{s} ; \mathrm{f}-90 \mathrm{MPa}, 140{ }^{\circ} \mathrm{C}, 3.49 \mathrm{~cm}^{3} / \mathrm{s}$; $\mathrm{g}-90 \mathrm{MPa}, 140{ }^{\circ} \mathrm{C}, 5.59 \mathrm{~cm}^{3} / \mathrm{s}$

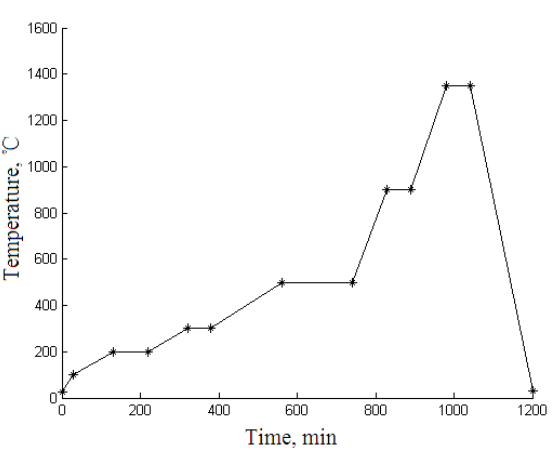

Fig. 5. Thermal debinding and sintering curve of 316L stainless steel

However, because all the parameters of the two groups are the same except the pressure (pressures of sample $\mathrm{A}$ and $\mathrm{F}$ are respectively $70 \mathrm{MPa}$ and $90 \mathrm{MPa}$ ), it can be speculated that the injection pressure has unapparent influence on the product defect to some extent. Comparing the sample $\mathrm{C}$ with $\mathrm{D}$, it can be seen that the porosity of $\mathrm{D}$ is less than that of $\mathrm{C}$ due to different injection temperatures of the two groups (temperature of sample $\mathrm{C}$ is $160{ }^{\circ} \mathrm{C}$, while that of $\mathrm{D}$ is $150^{\circ} \mathrm{C}$ ). Therefore, it is concluded that high temperature is expect to reduce viscosity of the feedstock significantly, which intensifies the two-phase separation and leads to more pores in sample C.

\section{CONCLUSIONS}

1. The FLUENT software was utilized to conduct numerical simulation on the severity of the two-phase separation of powder injection molding. It is found that the numerical simulation results are in good agreement with the injection molding test results, which proves that the two phase flow mixing model can be well applied to the simulation of injection molding.

2. As demonstrated in the results, the maximum average solid volume fraction in experimental area A of the
316L stainless steel sample was $57.68 \%$. The corresponding parameters of injection molding were to inject at $70 \mathrm{MPa}, 140{ }^{\circ} \mathrm{C}$, and $3.49 \mathrm{~cm}^{3} / \mathrm{s}$.

3. By observing and measuring the pores of metallographic microstructure in the surface of the sintered products, it was discovered that the higher average solid volume fraction leads to smaller and more uniform pores in the surface microstructure. This demonstrated that the slighter the degree of two-phase separation is, the better the two phases combine with each other. This can further provide evidence for the process optimization in the initial stage.

4. According to the Vickers hardness analysis performed on the samples, it was discovered that Vickers hardness of group $\mathrm{G}$ was the minimum, while that of group A was the maximum. Meanwhile, the more severe the two-phase separation, the smaller the Vickers harness was, and slighter two-phase separation led to higher Vickers hardness. This can provide references for optimizing process parameters.

\section{Acknowledgments}

The research described in this publication was made possible by financial support of the Natural Science Foundation of China (No.51004050 and No.51475235), the key research program of Jiangsu Province - industry outlook and common key technology project(No.BE2015100), the open Foundation of Jiangsu Key Laboratory of Large Engineering Equipment Detection and Control(No.JSKLEDC201506), Natural Science Foundation of Lianyungang (No. CG1418 and No. CG1514).

\section{REFERENCES}

1. Zhang, C., Xu, C. Metal Injection Molding. Chemical Industry Press, Beijing, 2007: pp. 1-2.

2. He, Y.Q., Chen, Z.H., Chen, Z.G., Qiao, B. Metal Injection Molding: Principle and Development Journal of Materials Science \& Engineering 31 (2) 2013: pp. 317-322. 
https://doi.org/10.14136/j.cnki.issn1673-2812.2013.02.033

3. Qu, X.H. Advance in Research of Powder Injection Molding Materials China 29 (5) 2010: pp. $42-47$.

4. Zhang, C., Xu, B. Application of Metal Powder Injection Molding in Automotive Industry Automobile Technology 4 2005: pp. 37-41.

https://doi.org/10.3969/j.issn.1000-3703.2005.04.011

5. Sidambe, A.T, Figueaoa, I.A., Hamilton, H.G.C., Todd, I. Metal Injection Moulding of CP-Ti Components for Biomedical Applications Journal of Materials Processing Technology 212 (7) 2012: pp. 1591-1597. https://doi.org/10.1016/j.jmatprotec.2012.03.001

6. Zhao, D., Chang, K., Ebel, T., Qian, M., Willumeit, R., Yan, M., Pyczak, F. Microstructure and Mechanical Behavior of Metal Injection Molded Ti-Nb Binary Alloys as Biomedical Meterial Journal of the Mechanical Behavior of Biomedical Materials 28 (6) 2013: pp.171-182. https://doi.org/10.1016/j.jmbbm.2013.08.013

7. Li, Y.M., Huang, B.Y., Zhong, W., Qu, X.H., Qiu, G.H. Influence of Processing Parameters on MIM Injection Defects in Compacts Rare Metal Materials \& Engineering 28 (2) 1999: pp. 117-120. https://doi.org/10.3321/j.issn:1002-185X.1999.02.014

8. Li, W., Shi, Q.N., Pei, H.Z., Zhang, G.L., Wang, X.Q. Product Performance Affected by Powder Injection Molding Process Parameters Development and Application of Materials 23 (1) 2008: pp. 31-34.

9. Li, L. The Powder Injection Molding of $\mathrm{ZrO}_{2}$ Samll Parts and The Dimension Precision Control. Ph.D. Harbin Institute of Technology, Harbin, China, 2007.

10. German, R.M., Bose, A. Injection Molding of Metals and Ceramics. Metal Powder Industries Federation, Princeton, NJ, 1997.
11. Shivashankar, T.S., $\quad$ Enneti, R.K., $\quad$ Park, S.J., German, R.M., Atre, S.V. The Effects of Material Attributes on Powder-Binder Separation Phenomena in Powder Injection Molding Powder Technology 243 (7) 2013: pp. $79-84$. https://doi.org/10.1016/j.powtec.2013.03.037

12. Wang, Y.H., Qu, X.H., He, X.B. Numerical Simulation Models of Powder Injection Molding Multiphase Filling Flow Process Journal of University of Science and Technology Beijing 29 (7) 2007: pp. 717-720. https://doi.org/10.13374/j.issn1001-053x.2007.07.015

13. Wang, Y.H., Qu, X.H., He, X.B., Zhang, Y, Zhao, L.M. Numerical Simulation of Unique Boundary Layer Effect during Powder Injection Molding Filling Flow Process Materials for Mechanical Engineering $32(5)$ 2008: pp. $77-80$.

https://doi.org/10.3969/j.issn.1000-3738.2008.02.023

14. Qiao, B., Dong, Y.F., Hu, J.B., Zhang, Y., Fu, J., Feng, L.C., He, Y.Q., Shang, F., Li, H.Q. Effect of Binder Ratio on Rheological Behavior of Feeding in Powder Injection Molding of 316L Stainless Steel Hot Working Technology 44 (14) 2015: pp. 70-73. https://doi.org/10.14158/j.cnki.1001-3814.2015.14.018

15. John, D. Anderson. Computational Fluid Dynamics. China Machine Press, Beijing, 2007: pp. 41-46.

16. Ganser, G.H. A rational approach to drag prediction of spherical and nonspherical particles Powder Technology 77 (2) 1993: pp. $143-152$. https://doi.org/10.1016/0032-5910(93)80051-B

17. Park, D.Y, Shin, D.S, Cho, H., Park, S.J. Effects of Material and Processing Conditions on Powder-Binder Separation Using the Taguchi Method Powder Technology 321 2017: pp. 369-379. https://doi.org/10.1016/j.powtec.2017.07.091 